\title{
Spectrofluorometric Determination of Lisinopril dihydrate and Methyl- Dopa in Bulk and Pharmaceutical Formulation by Using Dansyl Chloride
}

\author{
Sobhy M. El-Adl ${ }^{1}$, Mohamed El.Hossinny El-Sadek ${ }^{1}$, Nariman M. Saeed ${ }^{2 *}$ \\ ${ }^{1}$ Department of Medicinal Chemistry, Faculty of Pharmacy, Zagazig University, Zagazig, Egypt \\ ${ }^{2}$ Pharmacist, Ministry of Health, Egypt
}

*Corresponding Author: Nariman M. Saeed, Pharmacist, Ministry of Health, Egypt, Tel: (20-2) 7951821; Email: nariman_saeed@yahoo.com

Received: 17 January 2018; Accepted: 30 January 2018; Published: 01 February 2018

\begin{abstract}
A novel spectrofluorometric method has been developed for quantitative determination of Lisinopril dihydrate and methyldopa either in pure form or in pharmaceutical preparation. The principle of the method based on the reaction of each drug with dansyl chloride [5-(Dimethyl Amino) Naphthalene-1-Sulfonyl chloride] by the aid of sodium hydroxide solution of $\mathrm{pH} 8.5$ resulted in a product of a high fluorescent intensity which was then measured at 511 $\mathrm{nm}$ and $516 \mathrm{~nm}$, for lisinopril and methyldopa respectively after excitation at $323 \mathrm{~nm}$. Factors affecting reaction development were studied and optimized. The proposed method was found to be sensitive, selective and reproducible. Calibration curves were linear over the concentration ranges of 3-20 for lisinopril and 7-25 $\mu \mathrm{g} / \mathrm{mL}$ for methyldopa. Results obtained from tablets analysis were compared statistically with reported reference methods.
\end{abstract}

Keywords: Spectrofluorometric; Dansyl chloride; Lisinopril; Methyldopa

\section{Introduction}

Lisinopril dihydrate [LIS] (S)-1-[N2-(1-carboxy-3-phenylpropyl)-lysyl-proline dihydrate (Figure 1). It has a molecular formula of $\mathrm{C}_{21} \mathrm{H}_{31} \mathrm{~N}_{3} \mathrm{O}_{5} .2 \mathrm{H}_{2} \mathrm{O}$ and a molecular weight of $441.52 \mathrm{~g} / \mathrm{mol}$, official in BP and USP [1-2]. Lisinopril is non sulfhydryl long-acting angiotensin converting enzyme inhibitor used as antihypertensive agent, prophylactic after myocardial infarction, it exerts a haemodynamic action and allows natriuresis, it was also found to be useful in preventing diabetic retinopathy [3-4]. Several analytical methods, including spectrophotometric methods [5-7], spectrofluorometric [8-10], chromatographic methods [11-14], polarographic methods [15] and titrimetric method [16] have already been reported for its determination alone or in combination with other drugs. Methyl-dopa [MD] L-3-(3, 4- Dihydroxyphenyl)-2-methylalanine sesquihydrate (Figure 1), it is a catechol derivative with a molecular formula of $\mathrm{C}_{10} \mathrm{H}_{13} \mathrm{NO}_{4} .1 \frac{1}{2} \mathrm{H}_{2} \mathrm{O}$ and a molecular weight of $238.24 \mathrm{~g} / \mathrm{mol}$, official in USP 
[2]. "It is the drug of choice for hypertension in pregnancy". It acts centrally on alpha2-adrenoreceptor leading to a decrease in sympathetic tone causing blood pressure fall [3]. Several analytical methods, including spectrophotometric methods [17-22], spectrofluorometric [23], chromatographic methods [24, 25], titrimetric method [26] and Volta metric method [27] have been reported for its determination alone or in combination.

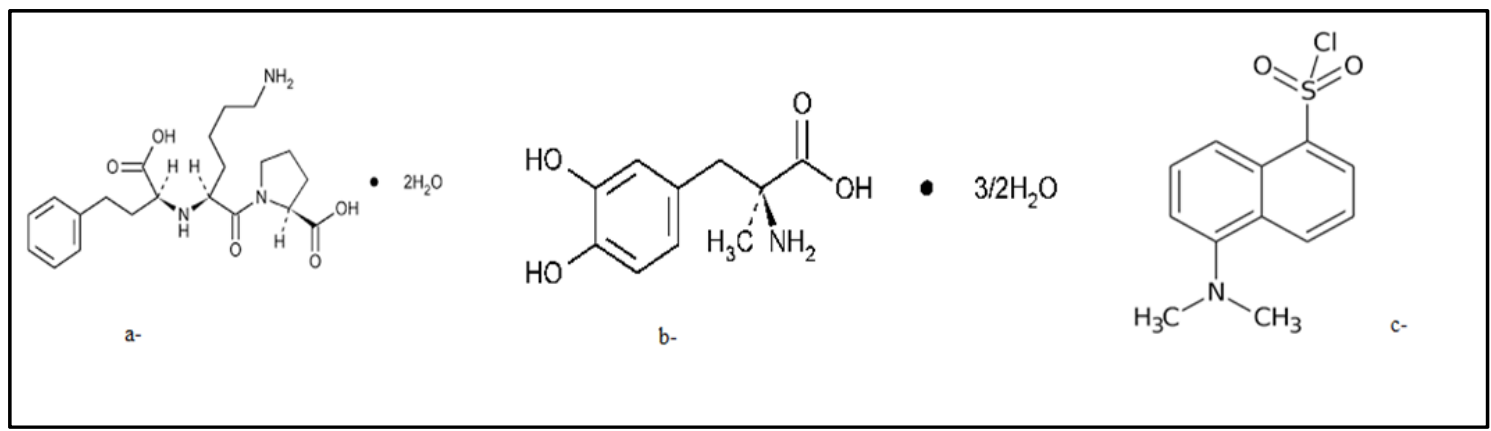

Figure 1: Chemical structure of [a-lisinopril], [b- methyldopa] and [c-dansyl-Cl].

\section{Experimental}

\subsection{Apparatus}

- Fluorescence measurements were carried out on a FP-6300 spectro-fluorimeter (Jasco, Japan) equipped with a $150 \mathrm{~W}$ xenon lamp and $1 \mathrm{~cm}$ quartz cells.

- Consort $\mathrm{P} 400^{\circledR}$ digital $\mathrm{pH}-$ meter for $\mathrm{pH}$ adjustment.

\subsection{Materials and reagents}

All solvents and reagents used throughout the work were of analytical grade and double distilled water was used.

Lisinopril pure authentic sample (99\%, purity) was kindly supplied by Rameda, Egypt. Sinopril ${ }^{\circledR}$ tablets, labeled to contain $10 \mathrm{mg}$ of lisinopril, batch no. b23205 (GNP, Egypt). Methyl dopa pure authentic sample (99.6\%, purity) was kindly supplied by Eipico, Egypt. Aldomet ${ }^{\circledR}$ tablets, labeled to contain 250mg of Methyldopa batch no. S420171 (KAHIRA, Egypt). Dansyl chloride (DNS-Cl) was purchased from Cornell Lab Company, solution of DNS-Cl was freshly prepared at $3.0 \mathrm{mg} / \mathrm{ml}$ in acetone. (Stable for one week). Sodium hydroxide was purchased from Research lab fine chemical industry, solution of $\mathrm{NaOH}$ was freshly prepared at $20 \mathrm{mg} / \mathrm{ml}$ in distilled water and $\mathrm{pH}$ was adjusted by $1 \mathrm{M}$ of $(34 \%) \mathrm{HCl}$ to 8.5 .

\subsection{General procedures}

2.3.1. Preparation of stock standard drug solution: A stock standard solution of lisinopril (1mg/ml) was prepared by weighing accurately $0.1 \mathrm{gm}$ of pure drug and dissolving in $100 \mathrm{ml}$ distilled water. stock standard solution of methyl dopa $(1 \mathrm{mg} / \mathrm{ml})$ was prepared by weighing accurately $0.1 \mathrm{gm}$ of pure drug and dissolving in $100 \mathrm{ml} \mathrm{methanol}$.

2.3.2. Preparation of working standard solution and construction of calibration curve: Aliqout containing from 1 to $25 \mu \mathrm{g} / \mathrm{mL}$ of (LIS) and (MD) was prepared by transferring certain increasing volume from each drug to a series of $10 \mathrm{ml}$ volumetric flasks, followed by adding $0.3 \mathrm{ml}$ of standard $\mathrm{NaOH}$, mixed well, then $0.5 \mathrm{ml}$ of standard (DNS-Cl) solution was added, mixed and left for 30 minutes for [LIS] and 35 minutes for [MD] in dark at $35^{\circ} \mathrm{C}$. 
The flasks were then cooled and the volume was completed to $10 \mathrm{ml}$ with methanol. The fluorescence intensity of the resulting solution was measured at 511 and $516 \mathrm{~nm}$ for (LIS) and (MD) respectively after excitation at $323 \mathrm{~nm}$ against reagent blank that had been treated similarly. The fluorescence intensity was plotted versus the final drug concentrations to get the calibration curve. The corresponding regression equation was computed.

\subsection{Application on pharmaceutical preparations}

Ten tablets of Sinopril ${ }^{\circledR}$ and five tablets of Aldomet ${ }^{\circledR}$ were crushed, powdered and the average weight of one tablet was determined. Then specific weight from each powdered drug equivelant to $100 \mathrm{mg}$ was dissolved in $100 \mathrm{ml}$ distilled water for sinopril ${ }^{\circledR}$ and methanol for aldomet ${ }^{\circledR}$ then filtered through whatman filter paper to give a final stock concentration of $1 \mathrm{mg} / \mathrm{ml}$ for each drug. Working solutions were prepared by serial dilution from stock solution. The procedures were then completed as previously mentioned using standard addition technique.

\section{Results and Discussion}

\subsection{Fluorescence spectra}

Both (LIS) and (MD) possess amino groups which have the ability to react with dansyl chloride in alkaline medium resulted in formation of a high fluorescent product, while the reagent blank exhibited a weak fluorescence intensity at the selected excitation and emission wavelengths under the optimized experimental conditions. Scheme 1 and 2) illustrates the suggested reaction path way for both drugs with dansyl chloride. Figure 2 and 3 explain the Fluorescence spectra for both drugs.

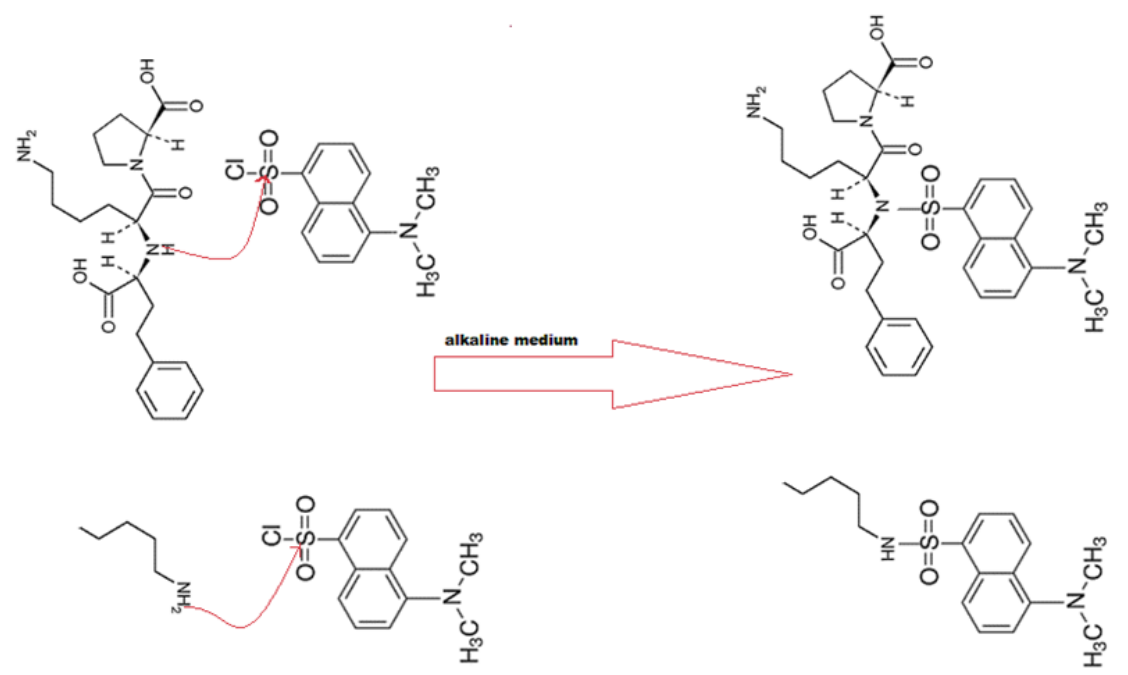

Scheme 1: Suggested reaction pathway between Lisinopril and dansyl chloride. 
<smiles>CN(C)c1cccc2c(S(=O)(=O)Cl)cccc12</smiles>

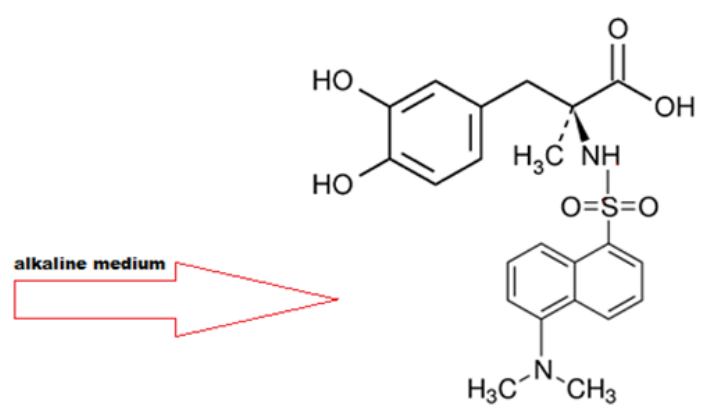

Scheme 2: Suggested reaction pathway between methyl dopa and dansyl chloride.

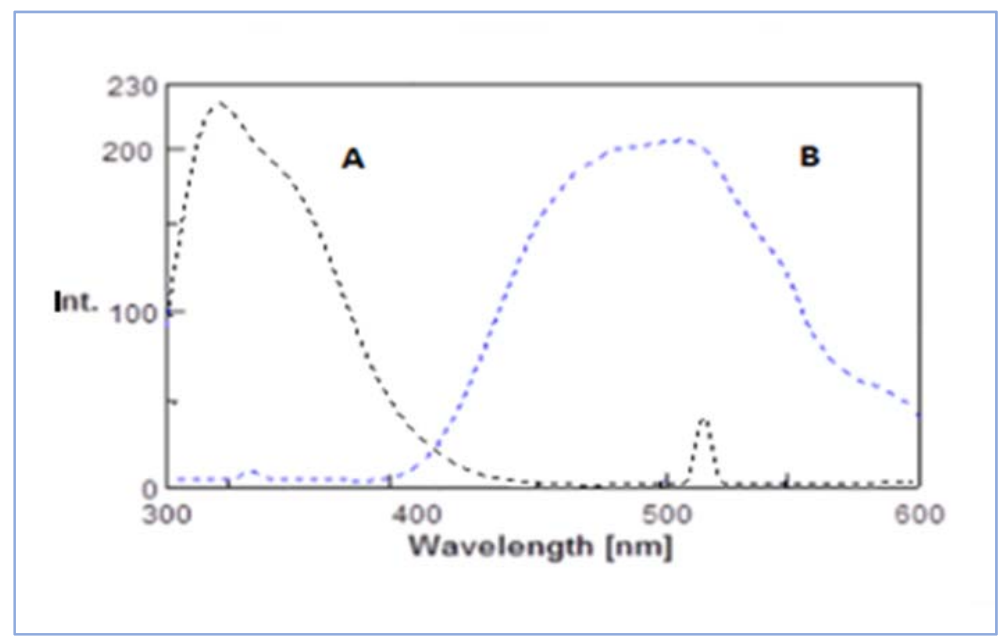

Figure 2: Excitation (A/black) and emission (B/blue) spectra of the LIS-DNS product ( $\lambda$ ex $=323 \mathrm{~nm}$ and $\lambda$ $\mathrm{em}=511 \mathrm{~nm})$.

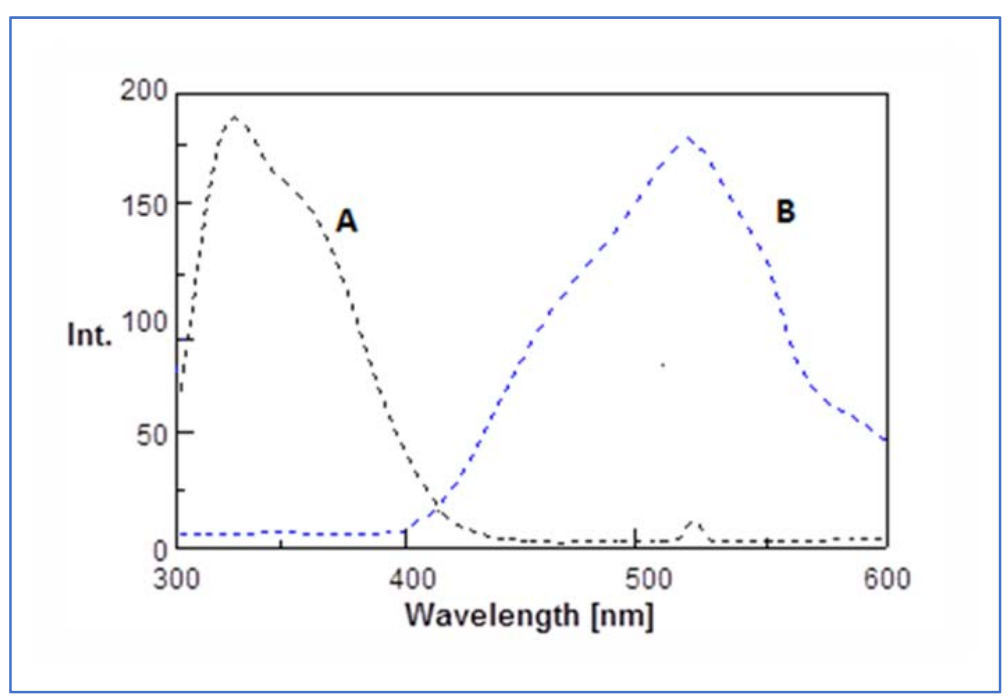

Figure 3: Excitation (A/black) and emission (B/blue) spectra of the MD-DNS product ( $\lambda$ ex $=323 \mathrm{~nm}$ and $\lambda$ $\mathrm{emm}=516 \mathrm{~nm})$. 


\subsection{Optimization of reaction conditions}

Different experimental factors including $\mathrm{pH}$, volume of buffer, amounts of reagent, temperature and reaction time were studied and optimized by changing each factor individually keeping the others constant.

3.2.1. Effect of $\mathrm{pH}$ : The influence of $\mathrm{pH}$ on the fluorescence intensity of the reaction product was examined using sodium hydroxide solution over the $\mathrm{pH}$ range from 6 to 11.0 since DNS-Cl reacts under alkaline conditions. The maximum fluorescence intensity was obtained when the reaction was carried out with $\mathrm{NaOH}$ solution of $\mathrm{pH}$ 8.5. Figure 4 illustrate the effect of $\mathrm{pH}$.

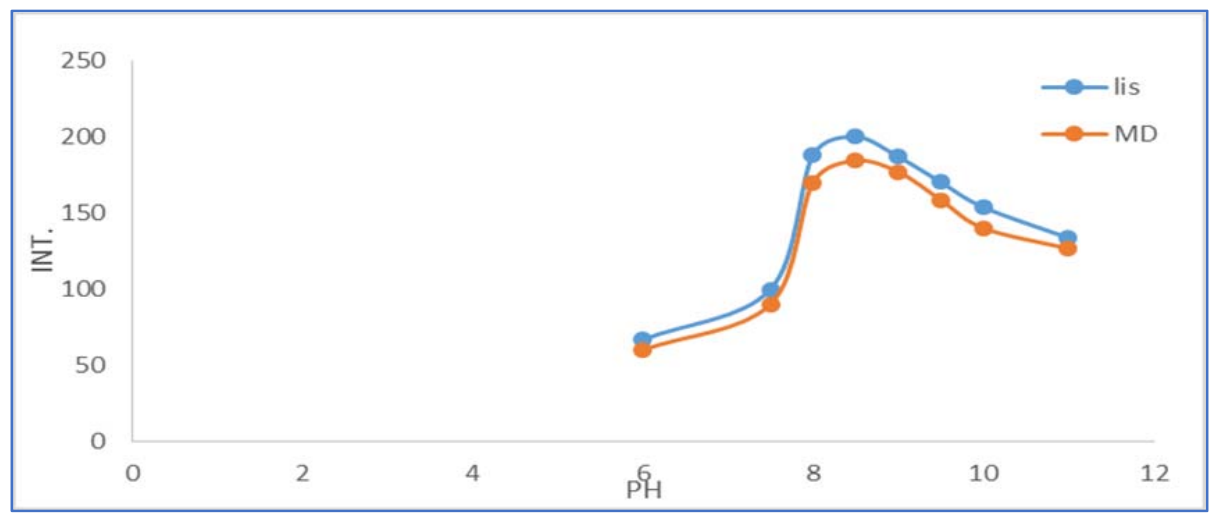

Figure 4: Effect of the $\mathrm{pH}$ on the development of the reaction product of (LIS) and (MD) (10 $\mu \mathrm{g} / \mathrm{mL})$ with DNS-Cl.

3.2.2. Effect of sodium hydroxide volume: The influence of volume of $\mathrm{NaOH}$ on the fluorescence intensity of the reaction product was examined using different volume over the range from 0.1 to $0.7 \mathrm{ml}$. Maximum fluorescence intensity was obtained when the reaction was carried out using $0.3 \mathrm{ml} \mathrm{NaOH}$ solution of $\mathrm{pH} 8.5$ as shown in Figure 5.

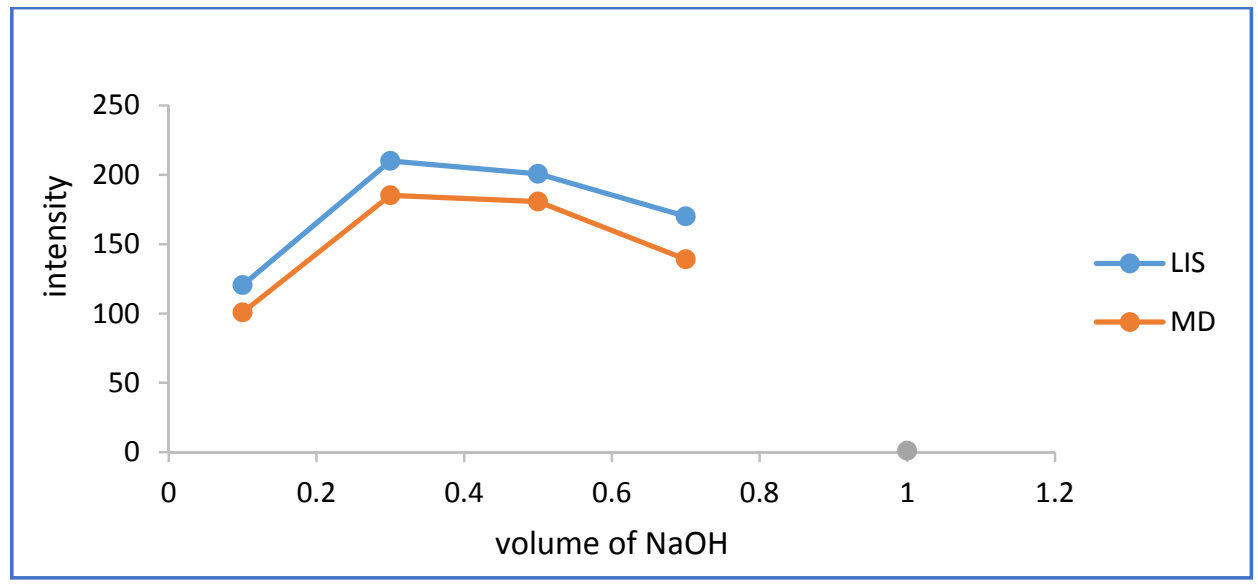

Figure 5: Effect of volume of $\mathrm{NaOH}$ solution on development of the reaction product of (LIS) and (MD) (10 $\mu \mathrm{g} / \mathrm{mL}$ ) with DNS-Cl. 
3.2.3. Effect of dansyl chloride volume: The influence of the volume of dansyl chloride solution was examined by addition of different volumes of $3.0 \mathrm{mg} / \mathrm{ml}$ reagent in the range of 0.2 to $1 \mathrm{ml}$. A maximum fluorescence intensity was obtained when $0.5 \mathrm{ml}$ of dansyl chloride solution was utilized as depicted in Figure 6 .

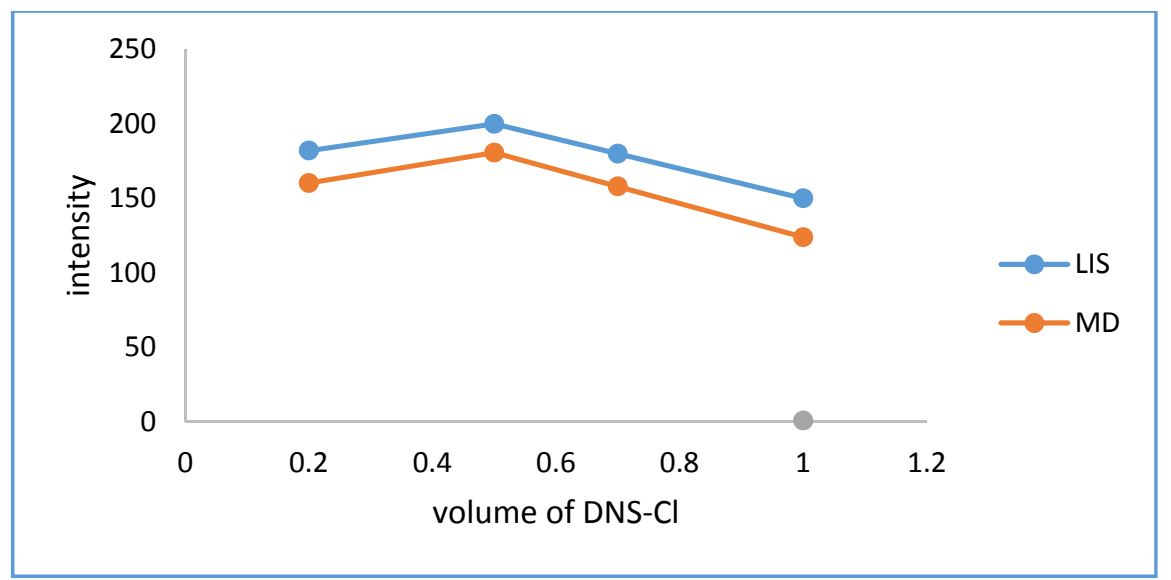

Figure 6: Effect of volume of DNS-Cl solution on development of the reaction product of (LIS) and (MD) (10

$$
\mu \mathrm{g} / \mathrm{mL}) \text {. }
$$

3.2.4. Effect of time and temperature: In this study, the reaction between the two drugs and dansyl chloride was performed using $\mathrm{pH} 8.5$ at different temperatures $\left(25^{\circ} \mathrm{C}, 35^{\circ} \mathrm{C}, 40^{\circ} \mathrm{C}\right.$, and $\left.50^{\circ} \mathrm{C}\right)$ for various time intervals $(10,20$, 30, 35 and $40 \mathrm{~min}$ ). As it is seen in Figure 7 and 8, the reaction was found to be completed after 30 and 35 min for (LIS) and (MD) respectively at $35^{\circ} \mathrm{C}$.

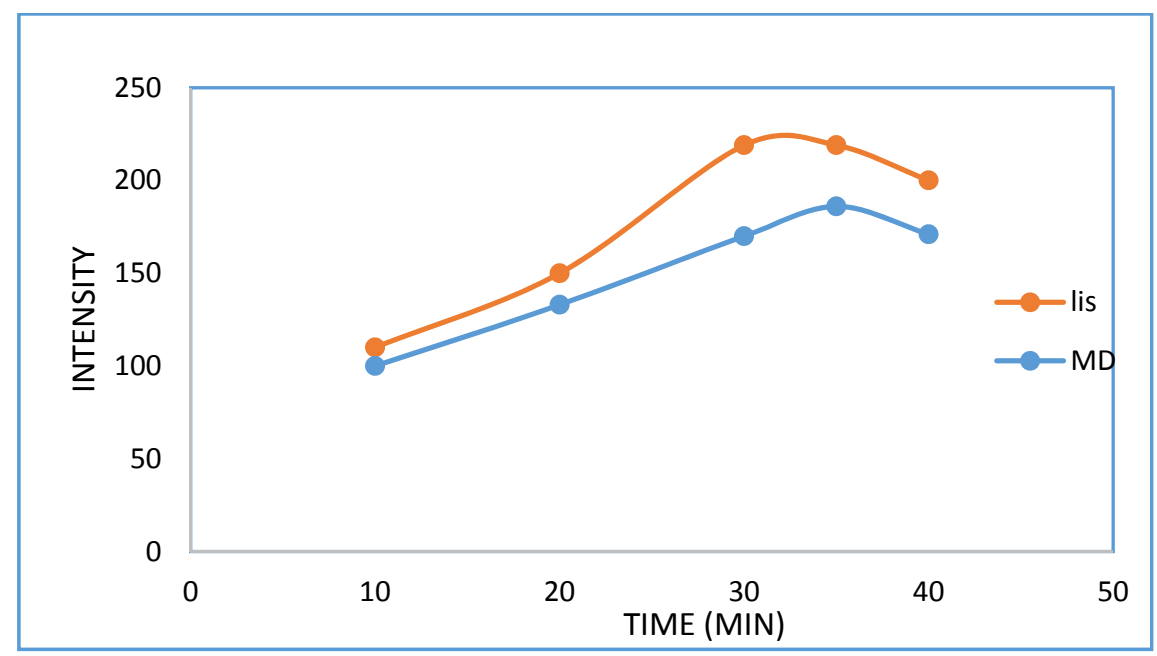

Figure 7: Effect of time on the reaction completion of (LIS) and (MD) $(10 \mu \mathrm{g} / \mathrm{mL})$ with DNS-Cl. 


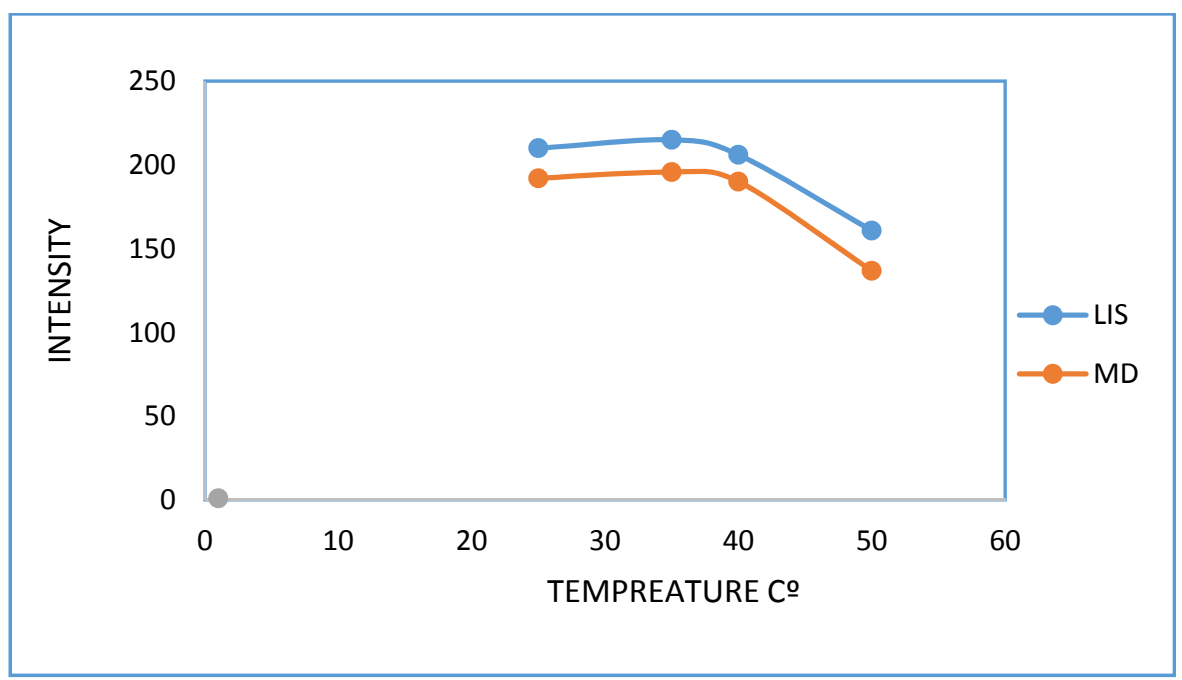

Figure 8: Effect of temperature on the reaction completion of (LIS) and (MD) $(10 \mu \mathrm{g} / \mathrm{mL})$ with DNS-Cl.

\subsection{Stoichiometry of the reaction}

The molar ratio of the reagent and the two drugs in the reaction was studied by using the continuous variation method (Job's method) [28]. The molar ratio was found to be 12 (drug: reagent) and 1:1 (drug: reagent) for Lisinopril and methyl- dopa respectively as seen in Figure 9.

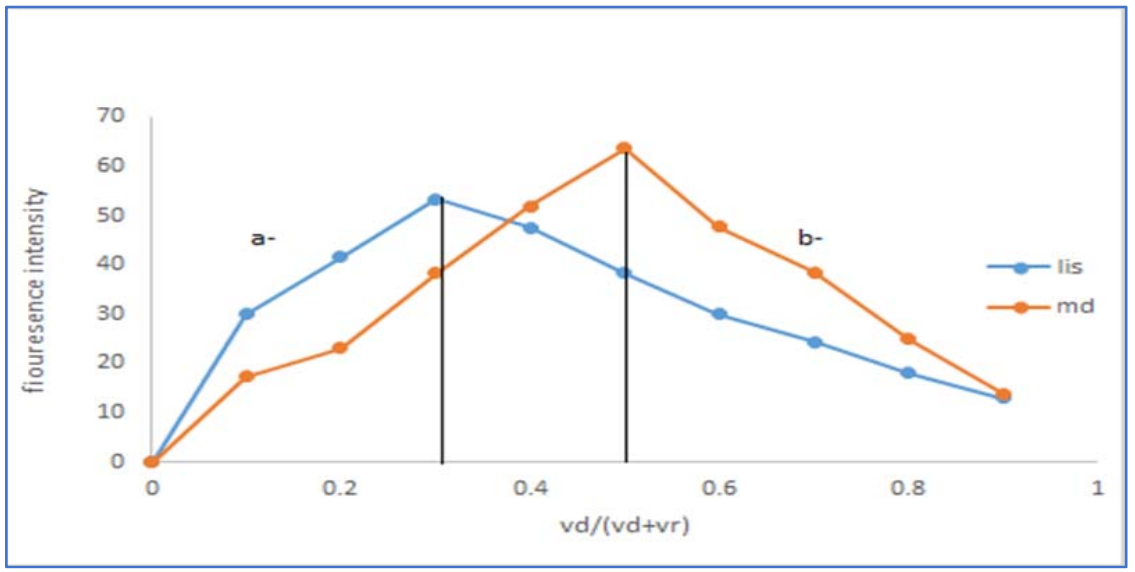

Figure 9: Continuous variation plots for the reaction between: (A) $2.26 \times 10-4 \mathrm{M}$ of DNS-Cl and 2.26 $\times 10-4 \mathrm{M}$ of Lisinopril and (B) $4.2 \times 10-4 \mathrm{M}$ of DNS-Cl and 4.2 $\times 10-4 \mathrm{M}$ of Methyl-dopa.

\subsection{Method validation}

The validity of the proposed method was tested regarding linearity, range, limits of detection, limits of quantification, accuracy, precision, robustness and specificity according to ICH recommendations [29].

3.4.1. Linearity: Under the optimum experimental conditions, standard calibration curves were constructed at five concentration levels by plotting the values of florescence intensity versus the final concentrations ( $\mu \mathrm{g} / \mathrm{ml})$ as shown in Figure 10. The correlation coefficient was 0.9999 and 0.9997 for (LIS) and (MD) respectively, indicating good 
linearity over the concentration range of 3.0 to 20.0 and 7.0 to $25.0 \mu \mathrm{g} / \mathrm{ml}$ for (LIS) and (MD) respectively. The intercept, slope, Correlation coefficient for the calibration data are summarized in Table 1. Calibration graph is described by the equation $(\mathrm{Y}=\mathrm{a}+\mathrm{bX})$, (Where $\mathrm{Y}=$ florescence intensity, $\mathrm{a}=$ intercept, $\mathrm{b}=$ slope and $\mathrm{X}=$ concentration in $\left.\mu \mathrm{g} \cdot \mathrm{ml}^{-1}\right)$.

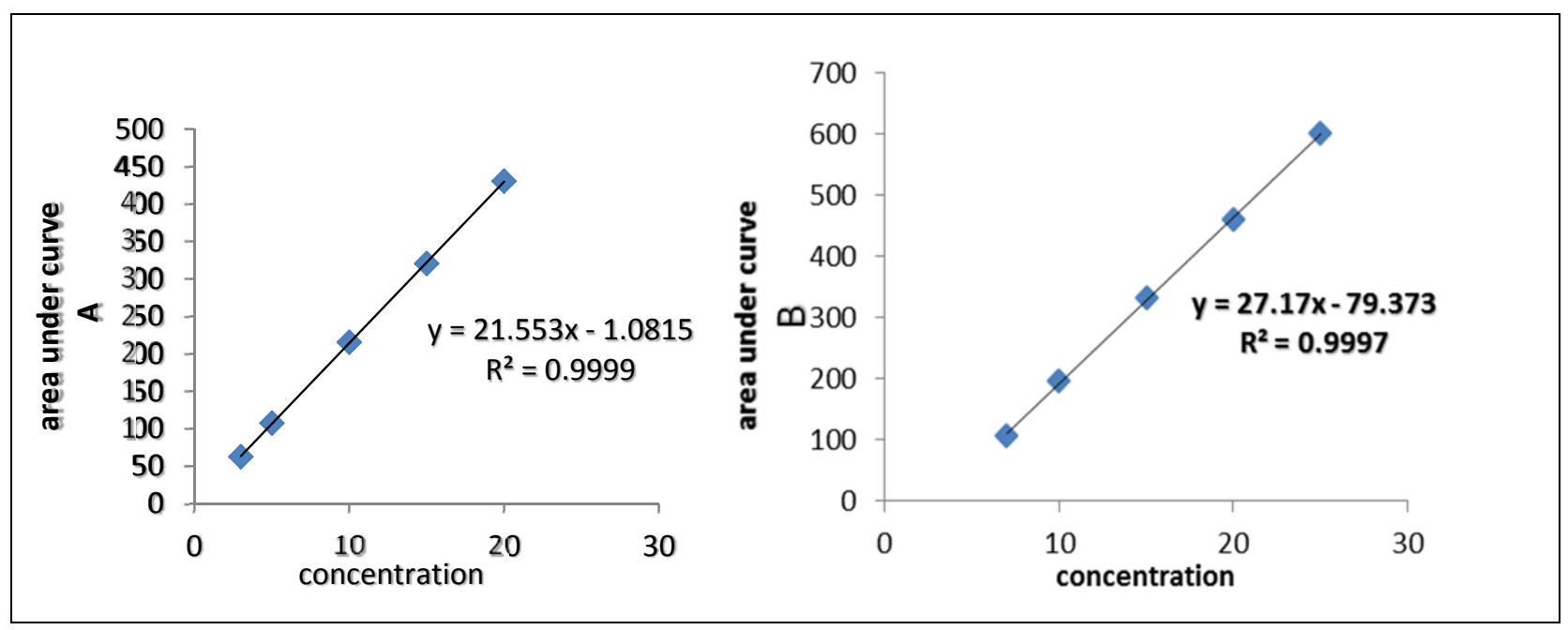

Figure 10: Calibration curves for the reaction between (DNS-CL) and (LIS) (A) and (MD) (B) respectively.

\begin{tabular}{|c|c|c|c|}
\hline \multicolumn{2}{|l|}{ Parameters } & Lisinopril & Methyl dopa \\
\hline \multicolumn{2}{|c|}{ Excitation wave length, nm } & 323 & 323 \\
\hline \multicolumn{2}{|c|}{ Emission wave length, $\mathrm{nm}$} & 511 & 516 \\
\hline \multicolumn{2}{|l|}{ pH } & 8.5 & 8.5 \\
\hline \multicolumn{2}{|l|}{ Volume of NaoH (ml) } & 0.3 & 0.3 \\
\hline \multicolumn{2}{|l|}{ (DNS-Cl) volume (ml) } & 0.5 & 0.5 \\
\hline \multicolumn{2}{|c|}{ Time for derivatization reaction } & 30 & 35 \\
\hline \multicolumn{2}{|l|}{ Temperature $\left({ }^{\circ} \mathrm{C}\right)$} & $35 \pm 2^{\circ} \mathrm{C}$ & $35 \pm 2^{\circ} \mathrm{C}$ \\
\hline \multicolumn{2}{|l|}{ Solvent } & water & Methanol \\
\hline \multicolumn{2}{|c|}{ Beer's law limits ( $\mu$ g.ml ${ }^{-1}$ ) } & $3-20$ & $7-25$ \\
\hline \multirow[t]{2}{*}{ Regression equation* } & Slope (b) & 1.0815 & 79.373 \\
\hline & Intercept (a) & 21.553 & 27.17 \\
\hline \multicolumn{2}{|l|}{ Correlation coefficient } & 0.9999 & 0.9997 \\
\hline
\end{tabular}

Table 1: Statistical and analytical parameters of (LIS) and (MD) determination. 
3.4.2. Limits of detection and limits of quantification: The limit of detection (LOD) was calculated according to the equation $[\mathrm{LOD}=3.3 \mathrm{~S} / \mathrm{K}]$. The limit of quantification $(\mathrm{LOQ})$ was calculated by the equation $[\mathrm{LOQ}=10 \mathrm{~S} / \mathrm{K}]$ Where $\mathrm{S}$ is the standard deviation of the three replicate determination and $\mathrm{K}$ is the slope of calibration graph. The results are summarized in Table 2.

\begin{tabular}{|c|c|c|c|c|c|c|}
\hline \multirow{3}{*}{ Parameters } & \multicolumn{3}{|l|}{ Lisinopril } & \multicolumn{3}{|l|}{ Methyl dopa } \\
\hline & $\begin{array}{l}\text { Conc.take } \\
\text { n }\end{array}$ & Conc.found & \multirow{2}{*}{$\begin{array}{l}\text { Recovery } \\
\%\end{array}$} & Conc.taken & Conc.found & \multirow{2}{*}{$\begin{array}{l}\text { Recovery } \\
\%\end{array}$} \\
\hline & $\mu \mathrm{g} / \mathrm{ml}$ & $\mu \mathrm{g} / \mathrm{ml}$ & & $\mu \mathrm{g} / \mathrm{ml}$ & $\mu \mathrm{g} / \mathrm{ml}$ & \\
\hline & 3 & 2.959 & 98.64 & 7 & 6.8779 & 98.2559 \\
\hline & 5 & 5.03788 & 100.757 & 10 & 10.124 & 101.241 \\
\hline & 10 & 10.0506 & 100.506 & 15 & 15.0958 & 100.638 \\
\hline & 15 & 14.922 & 99.482 & 20 & 19.8757 & 99.3785 \\
\hline & 20 & 20.0288 & 100.144 & 25 & 25.0266 & 100.106 \\
\hline Mean* & & & 99.9 & & & 99.92 \\
\hline $\mathbf{N}$ & & & 5 & & & 5 \\
\hline SD & & & 0.85 & & & 1.1575 \\
\hline RSD & & & 0.85 & & & 1.1584 \\
\hline SE & & & 0.427 & & & 0.5787 \\
\hline Variance & & & 0.729 & & & 1.3399 \\
\hline LOD,pgml $^{-1}$ & & & 0.264 & & & 0.2097 \\
\hline LOQ,pgml $^{-1}$ & & & 0.88 & & & 0.699 \\
\hline $\begin{array}{l}\text { Apparent } \\
\text { Molar } \\
\text { absorptivity** }\end{array}$ & & & \multirow[t]{2}{*}{9435577} & & & \multirow[t]{2}{*}{4957090} \\
\hline $\mathrm{L} \mathrm{Mol}^{-1} \mathbf{c m}^{-1}$ & & & & & & \\
\hline
\end{tabular}

*Mean of three different experiments; ** Calculated in the basis of molecular weight of the drug.

Table 2: Statistical data for the reaction of lisinopril and methyl dopa with dansyl chloride.

3.4.3. Accuracy and precision: Accuracy of the proposed methods was checked by performing recovery experiments through standard addition technique. The results are shown in Table 3 indicates good accuracy. The precision of the method was calculated in term of intermediate precision (intraday and inter-day). Three different concentrations five times of lisinopril and methyl dopa were analyzed during the same day (intra-day precision) and five consecutive days (inter-day precision). The standard analytical errors, relative standard deviations (RSD) and recoveries obtained by the proposed method were found to be acceptable. The results are summarized in Table 4. 


\begin{tabular}{|c|c|c|c|c|c|c|c|c|}
\hline & \multicolumn{4}{|c|}{ Sinopril ${ }^{\circledR}$ tablets } & \multicolumn{4}{|c|}{ Aldomet ${ }^{\circledR}$ tablet } \\
\hline & 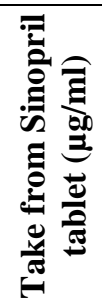 & 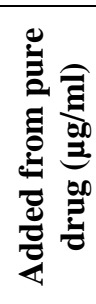 & 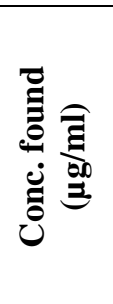 & 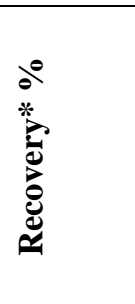 & 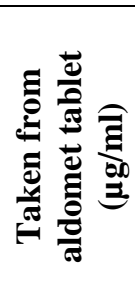 & 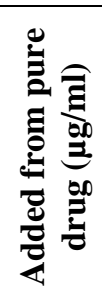 & 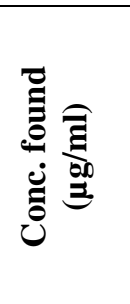 & 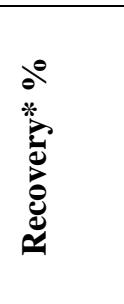 \\
\hline & 3 & 0 & 2.936 & 98 & 7 & 0 & 6.879 & 98.28 \\
\hline & 3 & 2 & 5.0237 & 100.474 & 7 & 3 & 10.1218 & 101.218 \\
\hline & 3 & 7 & 10.07 & 100.735 & 7 & 8 & 15.095 & 100.639 \\
\hline & 3 & 12 & 14.9 & 99.399 & 7 & 13 & 19.874 & 99.372 \\
\hline & 3 & 17 & 20.056 & 100.281 & 7 & 18 & 25.027 & 100.108 \\
\hline & 3 & 21 & 23.95 & 99.796 & - & - & - & - \\
\hline Mean* & - & - & - & 99.76 & - & - & - & 99.923 \\
\hline $\mathbf{N}$ & - & - & - & 6 & - & - & - & 5 \\
\hline S.D. & - & - & - & 1.03595 & - & - & - & 1.14 \\
\hline R.S.D. & - & - & - & 1.0384 & - & - & - & 1.14 \\
\hline $\mathbf{V}$ & - & - & - & 1.07 & - & - & - & 1.3 \\
\hline S.E. & - & - & - & 0.5179 & - & - & - & 0.57 \\
\hline
\end{tabular}

* Mean of three different experiments.

Table 3: Application of standard addition technique for the determination of Sinopril $®$ and Aldomet $₫$ tablets form through reaction with DNS-Cl.

\begin{tabular}{|c|l|l|l|l|l|}
\hline \multirow{2}{*}{ Item } & \multirow{2}{*}{$\begin{array}{c}\text { Concentration } \\
\mu \mathrm{g} / \mathrm{ml}\end{array}$} & \multicolumn{1}{|c|}{ Intraday } & \multicolumn{2}{c|}{ Inter-day } \\
\cline { 3 - 6 } & $10 \mu \mathrm{g} / \mathrm{ml}$ & $100.5 \pm 0.15$ & 0.15 & $100.46 \pm 0.28$ & 0.28 \\
\hline \multirow{5}{*}{ Lisinopril } & $15 \mu \mathrm{g} / \mathrm{ml}$ & $99.655 \pm 0.244$ & 0.245 & $99.2 \pm 1.23$ & 1.24 \\
\cline { 2 - 6 } & $20 \mu \mathrm{g} / \mathrm{ml}$ & $100.117 \pm 0.1688$ & 0.1686 & $100.108 \pm 0.29$ & 0.29 \\
\hline \multirow{3}{*}{ Methyldopa } & $10 \mu \mathrm{g} / \mathrm{ml}$ & $101.156 \pm 0.4$ & 0.39 & $101.2 \pm 0.63$ & 0.62 \\
\cline { 2 - 6 } & $15 \mu \mathrm{g} / \mathrm{ml}$ & $100.465 \pm 0.197$ & 0.196 & $100.6 \pm 0.208$ & 0.206 \\
\cline { 2 - 6 } & $20 \mu \mathrm{g} / \mathrm{ml}$ & $99.19 \pm 0.185$ & 0.1867 & $99.349 \pm 0.637$ & 0.642 \\
\hline
\end{tabular}

Table 4: Results of the intraday and inter-day precision for the determination of lisinopril and methyl dopa using DNS-Cl. 
3.4.5. Robustness: Robustness was achieved by making small incremental change in volume of sodium hydroxide and volume of reagent. The effect of changes was studied on the percent recovery of drugs proved that all changes had a negligible influence on the results as seen in Table 5.

\begin{tabular}{|l|l|l|}
\hline \multicolumn{3}{|c|}{ Robustness } \\
\hline \multicolumn{3}{|c|}{ \% of recovery \pm SD } \\
\hline Item & Lisinopril & Methyl dopa \\
\hline $\mathrm{NaOH}+0.05 \mathrm{ml}$ & $99.9 \pm 0.814$ & $\mathbf{9 9 . 9} \pm \mathbf{1 . 6 5}$ \\
\hline $\mathrm{Na} 0 \mathrm{H}-0.05 \mathrm{ml}$ & $99.99 \pm 0.716$ & $\mathbf{9 9 . 9} \pm \mathbf{1 . 1 5}$ \\
\hline $\mathrm{DNS}-\mathrm{Cl}+0.05 \mathrm{ml}$ & $99.8 \pm 1.17$ & $\mathbf{9 9 . 9} \pm \mathbf{0 . 8 8 8}$ \\
\hline DNS-Cl-0.05ml & $99.88 \pm 0.8$ & $\mathbf{9 9 . 9 4 8} \pm \mathbf{0 . 7}$ \\
\hline
\end{tabular}

Table 5: Results of the robustness for the determination of lisinopril and methyl dopa using DNS-Cl.

3.4.6. Analysis of pharmaceutical preparations: The proposed methods were applied to the analysis of the drug in dosage forms and the results were statistically compared with reported reference methods by calculating Student's $t$ and F-values. The evaluated $t$-and F-values were less than the tabulated values at the $95 \%$ confidence level. Results listed in Table 6 showing that there is no statistical significance difference between the proposed and reference methods.

\begin{tabular}{|l|l|l|l|l|}
\hline \multirow{2}{*}{ Statistics } & \multicolumn{3}{c|}{ Sinopril $^{\circledR}$ tablet } & \multicolumn{2}{c|}{ Aldomet $^{\circledR}$ tablet $^{*}$} \\
\cline { 2 - 5 } & $\begin{array}{c}\text { Reported reference } \\
\text { method number [133] }\end{array}$ & $\begin{array}{c}\text { Proposed } \\
\text { method }\end{array}$ & $\begin{array}{c}\text { Reported reference } \\
\text { method number } \\
{[153]}\end{array}$ & $\begin{array}{c}\text { Proposed } \\
\text { method }\end{array}$ \\
\hline Mean recovery* \pm SD & $100.33 \pm 0.7$ & $99.76 \pm 1.0359$ & $100.1 \pm 1.2$ & $99.9 \pm 1.14$ \\
\hline N & 6 & 6 & 5 & 5 \\
\hline Variance & 0.49 & 1.07 & 1.44 & 1.3 \\
\hline t-test** & - & $1.1(2.23)^{\mathrm{a}}$ & - & $0.27(2.3)^{\mathrm{a}}$ \\
\hline F-ratio** & - & $2.18(5.05)^{\mathrm{b}}$ & - & $1.1(6.39)^{\mathrm{b}}$ \\
\hline
\end{tabular}

* Average of three experiments; ${ }^{\mathrm{a}}$ and ${ }^{\mathrm{b}}$ are Theoretical Student $\mathrm{t}$-values and F- ratio at $\mathrm{p}=0.05$.

Table 6: Statistical data for the determination of pharmaceutical tablets Sinopril ${ }^{\circ}$ and Aldomet ${ }^{\circledR}$ through the proposed methods using DNS-Cl compared with the reference methods.

\section{Conclusion}

The proposed method was simple, fast, selective, sensitive, specific, reproducible and not very expensive. Validation experiments proved that results were linear over the mentioned working range. No interference was observed from the described drugs and their common excipients. Also there was no need for extraction procedure. 


\section{Acknowledgment}

Authors are grateful to all members of staff of Medicinal chemistry department (Zagazig University) also to all members of staff of analytical chemistry department and laboratories staff (Tanta University)

\section{References}

1. Berenguer M. Systematic review of the treatment of established recurrent hepatitis C with pegylated interferon in combination with ribavirin. J Hepatol 49 (2008): 274-287.

2. Wang CS, Ko HH, Yoshida EM, et al. Interferon-based combination anti-viral therapy for hepatitis $\mathrm{C}$ virus after liver transplantation: A review and quantitative analysis. Am J Transplant 6 (2006): 1586-1599.

3. Coilly A, Roche B, Dumortier J, et al. Safety and efficacy of protease inhibitors to treat hepatitis C after liver transplantation: A multicenter experience. J Hepatol 60 (2014): 78-86.

4. Butt AA, Kanwal F. Boceprevir and Telaprevir in the Management of Hepatitis C Virus-Infected Patients. ClinInfect Dis 54 (2012): 96-104.

5. Sundaram V, Kowdley KV. Dual daclatasvir and sofosbuvir for treatment of genotype 3 chronic hepatitis $\mathrm{C}$ virus infection. Expert Rev GastroenterolHepatol 10 (2016): 13-20.

6. Liao H, Tan P, Zhu Z, et al. Sofosbuvir in combination with daclatasvir in liver transplant recipients with HCV infection: A systematic review and meta-analysis.Clin Res HepatolGastroenterol 41 (2017): 262-271.

7. Sumathi K, Thamizhvanan K, Vijayraj S. Development and validation of stability indicating RP-HPLC method for the estimation of Daclatasvir in bulk and formulation. Der Pharm Lett 8 (2016): 107-113.

8. Ariaudo A, Favata F, De Nicolò A, et al. A UHPLC-MS/MS method for the quantification of direct antiviral agents simeprevir, daclatasvir, ledipasvir, sofosbuvir/GS-331007, dasabuvir, ombitasvir and paritaprevir, together with ritonavir, in human plasma. J Pharm Biomed Anal 125 (2016): 369-375.

9. Chakravarthy VA, Sailaja BBV. Method development and validation of assay and dissolution methods for the estimation of daclatasvir in tablet dosage forms by reverse phase HPLC. Eur J Pharm Med Res 3 (2016): 356364.

10. Jiang H, Kandoussi H, Zeng J, et al. Multiplexed LC-MS/MS method for the simultaneous quantitation of three novel hepatitis $\mathrm{C}$ antivirals, daclatasvir, asunaprevir, and beclabuvir in human plasma. J Pharm Biomed Anal 107 (2015): 409-418.

11. Nannetti G, Messa L, Celegato M, et al. Development and validation of a simple and robust HPLC method with UV detection for quantification of the hepatitis $\mathrm{C}$ virus inhibitor daclatasvir in human plasma. J Pharm Biomed Anal 134 (2017): 275-281.

12. Rezk MR, Bendas ER, Basalious EB, et al. Development and validation of sensitive and rapid UPLC-MS/MS method for quantitative determination of daclatasvir in human plasma: Application to a bioequivalence study. $\mathrm{J}$ Pharm Biomed Anal 128 (2016): 61-66.

13. Srinivasu G, Kumar KN, Thirupathi C, et al. Development and Validation of the Chiral HPLC Method for Daclatasvir in Gradient Elution Mode on Amylose-Based Immobilized Chiral Stationary Phase. Chromatographia79 (2016): 1457-1467. 
14. Azab SM, Fekry AM. Electrochemical design of a new nanosensor based on cobalt nanoparticles, chitosan and MWCNT for the determination of daclatasvir: a hepatitis C antiviral drug. RSC Adv 7 (2017): 1118-1126.

15. Hassouna MEM, Abdelrahman MM, Mohamed MA. Assay and Dissolution Methods Development and Validation for Simultaneous Determination of Sofosbuvir and Ledipasvir by RP-HPLC Method in Tablet Dosage Forms. J Forensic SciCrimInvestig 1 (2017): 555-562.

16. Elkady EF, Aboelwafa MA. A Rapid and Optimized LC-MS/MS Method for the Simultaneous Extraction and Determination of Sofosbuvir and Ledipasvir in Human Plasma. J AOAC Int 99 (2016): 1252-1259.

17. Ravichandran V, Shalini S, Sundram K, et al. Validation of analytical methods-strategies \& importance. J Pharm PharmSci 2 (2010): 18-22.

18. Swain D, Samanthula G, Bhagat S, et al. Characterization of forced degradation products and in silico toxicity prediction of Sofosbuvir: A novel HCV NS5B polymerase inhibitor, J Pharm Biomed Anal 120 (2016): 352363.

19. Pan C, Chen Y, Chen W, et al. Simultaneous determination of ledipasvir, sofosbuvir and its metabolite in rat plasma by UPLC-MS/MS and its application to a pharmacokinetic study, J Chromatogr B 1008 (2016): 255259.

20. Rezk MR, Basalious EB, Karim IA. Development of a sensitive UPLC-ESI-MS/MS method for quantification of sofosbuvir and its metabolite, GS-331007, in human plasma: Application to a bioequivalence study, J Pharm Biomed Anal 114 (2015): 97-104.

21. Rezk MR, Bendas ER, Basalious EB, et al. Quantification of sofosbuvir and ledipasvir in human plasma by UPLC-MS/MS method: Application to fasting and fed bioequivalence studies, J Chromatogr B 1028 (2016): $63-70$.

22. Shi X, Zhu D, Lou J, et al. Evaluation of a rapid method for the simultaneous quantification of ribavirin, sofosbuvir and its metabolite in rat plasma by UPLC-MS/MS. J Chromatogr B 1002 (2015): 353-357.

23. Topagi KS, Jeswani RM, Sinha PK, et al. A validated normal phase HPLC method for simultaneous determination of drotaverine hydrochloride and omeprazole in pharmaceutical formulation, Asian $\mathrm{J}$ PharmClinic Res 3 (2010): 20-24.

24. Rajeev KG, Anand C, Brijeshkunvar M. Simultaneous estimation of propafenone and its two metabolites in human plasma by liquid chromatography/tandem mass spectrometry LC-MS/MS. Int J Pharm PharmSci 9 (2017): 192-199.

25. Himaja M, Kalpana J, Anbarasu C. Validated zero order and first order derivative spectrophotometric methods for invitro analysis of Tenofovir disoproxil fumarate tablets using azeotropic mixture, Int J Pharm PharmSci 6 (2014): 302-304.

26. Lakshmi K, Rajesh T, Sharma S. Simultaneous determination of metformin and pioglitazone by reversed phase HPLC in pharmaceutical dosage forms, Int J Pharm PharmScil (2009): 162-166.

27. Armstrong DW, Zhang B. Product review: chiral stationary phases for HPLC. ACS Publications 2001: 557.

28. Vikas K, Sachin G, Omprakash B. Development, Validation and Stability Study of UV Spectrophotometric Method for Determination of Daclatasvirin Bulk and Pharmaceutical Dosage Forms.Int J ChemTech Res 10 (2017): $281-287$. 
29. Jeevana JB, Padmaja G. UV spectrophotometric method for estimation ofnew drug, Daclatasvir dihydrochloride, Int Res J Pharm 7 (2016): 1-3.

30. Hanaa S, Gamal HR, Mohamed AO. Stability indicating hplc method development and validation for determination of daclatasvir in pure and tablets dosage forms. Indo Am J Pharm Sci3 (2016): 1565-1572.

31. Ashok CV, Sailaja BBV, Praveen KA. Method development and validation of ultraviolet-visible spectroscopic method for the estimation of hepatitis-c drugs - daclatasvir and sofosbuvir in active pharmaceutical ingredient form, Asian JPharmClin Res 9 (2016): 61-66.

Citation: Sobhy M. El-Adl, Mohamed El.Hossinny El-Sadek, Nariman M. Saeed. Spectrofluorometric Determination of Lisinopril dihydrate and Methyl- Dopa in Bulk and Pharmaceutical Formulation by Using Dansyl Chloride. J Pharm Pharmacol Res 2 (2018): 001-014.

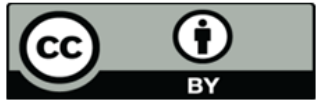

